\title{
Enhancing Reflection and Empathy Skills via Using a Virtual Reality Based Learning Framework
}

\author{
https://doi.org/10.3991/ijet.v14i07.9946 \\ Kalliopi-Evangelia Stavroulia( $\left({ }^{\bowtie}\right)$ \\ Cyprus University of Technology, Limassol, Cyprus \\ kalliopi.stavroulia@cut.ac.cy \\ Andreas Lanitis \\ Cyprus University of Technology, Limassol, Cyprus \\ Research Centre on Interactive Media Smart Systems and Emerging Technologies, Limassol, \\ Cyprus
}

\begin{abstract}
The last few years Virtual Reality (VR) based approaches have emerged as a new education paradigm. This paper addresses the possibility to cultivate reflection and empathy skills using a VR based framework targeting to maximize the professional development of teachers. Reflection and empathy are skills of paramount importance for teachers and an integral part of their professional development. The current research aims to investigate possible differences in cultivating reflection and empathy skills between participants who used a VR system and the control group who were trained in a real classroom environment. Experimental results indicate that the participants using the virtual classroom environment were able to better reflect and empathize with the students whereas participants from the control group tended to be more undecided. Moreover, the VR system gave the participants the opportunity to enter the students' virtual body and understand the different perspectives affecting at a higher level the reflection process than the control group.
\end{abstract}

Keywords-Teachers, reflection, empathy, virtual reality

\section{$1 \quad$ Introduction}

Today's societies are plagued by constant changes brought about by the rapid technological evolution of recent years. The new technological trends led to the transformation of the educational systems globally and to the digitalization of today's classroom, making teaching an even more complex and dynamic process that requires highly skilled teachers able to deal with unforeseen challenges that arise within the school context. Thus, teacher's professional development and high-quality expertise is of paramount importance and the key that will eventually maximize the quality of education.

Teachers are the heart of every school or educational institution in all levels. Hence, the quality of their training, starting from Initial Teacher Education (ITE) to 
career-long professional development, plays a crucial role for the quality of teaching and student management that shapes the future generations [1]. ITE is a teacher's first step of a long journey in teacher training and development. However, research reveals that ITE programs do not adequately prepare pre-service teachers towards today's challenges, while most teacher education programs are still very theoretical and disconnected from the school environment [2][3][4][5][6]. As a result, the knowledge gained at University courses is not sufficient for confronting the classroom, while the lack of classroom practice and of strong communication channels between universities and schools does not provide new teachers with experiences related to realistic inschool situations [4]. Furthermore, nowadays classrooms are characterized by heterogeneity and an increasing number of pupils who whose first language is not the official language of the school. Consequently, teachers need to respond to this multicultural challenge, understand student's different cultural backgrounds and needs, while they must treat all students equally and individualize learning.

This paper presents a proposal for the improvement of teacher education via using a VR based approach as part of teacher education framework that will allow teachers to experience an entirely new side of training. The article analyzes one of the first attempts, at least to the best of our knowledge, to use a VR based framework to educate teachers. Moreover, the VR system and scenarios were designed based on an extensive literature review research, surveys and interviews with teachers and experts to address real needs of teachers maximizing the effectiveness of the VR system. Furthermore, the VR system targets the cultivation of specific competencies and specifically reflection and empathy, derived from an extensive documentation of existing Teachers' Competence Models and significant guidance by experts who pointed specific competencies of primary importance to teachers. VR can provide teachers an absorbing, realistic and interactive virtual classroom space, allowing them to virtually experience real life classroom scenarios. Within the virtual world teachers can experience real-life situations, test their knowledge and decide the appropriate course of action, but within a safe environment that minimizes the risk of harming real students. The paper presents an experiment that aimed to investigate the possibility of using a VR-based approach aiming to enhance teacher's reflection and empathy skills. Additionally, the experiment aimed to identify possible differences between the groups that used the VR system and those who were trained in a real classroom without using the VR system.

\section{Literature Review}

\subsection{VR-based approach in teacher education to enhance reflection skills}

The past few years, there is a growing interest of the scientific community to take advantage of VR technology in the field of education [7]. Nevertheless, research regarding the use of virtual reality environment (VRE) - based educational interventions in teacher training is still at its infancy and there is limited yet growing body of research indicating the potential of using such an approach [8]. 
The first attempts of using VR based learning for teacher education regarding issues such as bullying, and recognition of student's vision disorders yield promising findings [9][10]. Moreover, the use of VR environments is very useful in domains complex and difficult to master, and as such it is well suited for teacher professional development. VR has the potential to become an innovative and essential tool in teacher training offering teachers the room for experimentation but without the risk of harming real students [11]. Equally important is the fact that the knowledge gained using VR can be applied to real life and thus teachers will be able to apply the knowledge gained in their real classroom [12][13][14]. Moreover, such a VR system can offer users the opportunity to record their performance, reflect on it and experiment again supporting in that way the enhancement of teaching performance [13][15].

Taking all the above into consideration, this paper proposes the use of a VR tool for the development of effective future teachers that will be successful in the classroom, while constant training within the virtual environment will ensure their survival in todays' digital and multicultural classrooms. This research aims to give an innovative VR-based approach to teacher education and the related training methodology that will allow in-service and pre-service teachers to experience an entirely new side of training. Moreover, the use of VR in teacher training responds to a real need from the European Union [1] for improving the development of teaching practices and attracting more high-quality candidates to the teaching profession. The aim of this research is to offer a new paradigm in teacher training, an alternative safe and lowcost environment that allow users to learn from their mistakes without consequence for the students. The proposed virtual reality tool aims to provide strong support for teachers' professional development through high-quality scenarios that address real needs of teachers. Moreover, the VR tool addresses specific teachers' competences as outcome, after an extensive documentation of existing Teachers' Competence Models and significant guidance by experts who pointed specific competencies of primary importance to teachers.

The implementation of the VR based approach followed a full designed cycle, a five-phase process influenced by the ADDIE model (Analysis, Design, Development, Implementation, Evaluation). The development of the VR system is linked to both strong theoretical foundations in education derived from the literature, and real teachers' problems based on extensive literature analysis and survey. The VR based approach allows users to construct knowledge from facts and improve their teaching practice via recalling their own experiences and reflecting on them [16][17]. Furthermore, VR offers the possibility to experience a range of professional situations while it also includes the element of repetition. A professional practitioner, experiences various situations repeatedly and through reflection he/she can criticize and think back the situations he/she experienced maximining his/her knowledge and understanding and be prepared for future situations [18]. Thus, a teacher within a VR environment can encounter a certain situation repeatedly and through experimentation and constant practice to be able to respond in a similar situation in the real class-room context. 


\subsection{The five-stages for the development of the VR system}

The development of the VR system progressed through the five stages of Analysis, Design, Development, Implementation and Evaluation of instructional design that is being used widely for the development of training programs [19][20]. The five stages constitute a set of activities that target specific outcomes [21]. More specifically, the five stages are:

Phase 1: Analysis and investigation of teacher's real training needs through literature review research, survey and interviews with teachers and experts.

Phase 2: Designing the competency framework for the proposed Virtual Realitybased investigation. Addressing all teacher's competencies included in the various models is unmanageable at this stage, thus, a selection of competencies had to be made based on the indications by teachers and experts. Hence, the proposed VR system aims to enhance reflection and empathy skills.

Phase 3: Design of the scenarios

Phase 4: Development of the VR system

Phase 5: Implementation and evaluation of the effectiveness of the VR system

\subsection{Reflection in teacher education: significance and challenges}

Reflection comes from the Latin word 'reflectere' that means to turn back [22] and it is not a new concept, but it can be traced back to ancient times as Socrates and Plato were the first to use the process of reflection. Even though the concept of reflection has been around for a long time, the educational systems became capable of integrating reflection skills in the 18th century when education was treated as part of the total social system [23]. For this reason, the social context and its influence on the school environment cannot be omitted during the process of reflection and should be taken into consideration by teachers when reflecting on their work [24] [25]. Neglecting the social conditions that influence today's classrooms, especially nowadays that the societies have become multicultural posing enormous challenges, will lead to teachers who are incapable to confront the transformation and modernization of the educational system and ineffective to achieve the educational goals and prepare today's students for tomorrow.

There is no single definition of the concept of reflection but a variety of classifications representing the different viewpoints of the theorists that used the term. Dewey [26] defines As stated in Ref. [26] reflection is an 'active, persistent, and careful consideration of any belief or supposed form of knowledge in the light of grounds that support it, and the further conclusions to which it tends'. Reflection is an everyday process, 'an important human activity in which people recapture their experience, think about it, mull it over and evaluate it' [27]. Additionally, reflection is a learning mechanism that includes the process of stepping back from an experience and through extensive consideration get a better and deeper understanding of a phenomenon [28].

Reflection has been considered as a skill of paramount importance for teachers and an integral part of their professional development [29]. As stated in Ref. [30] teacher education programs should emphasize on the promotion of reflection skills that will 
help teachers understand the connection between theory and practice maximizing their effectiveness. Reflection can promote the development of new knowledge regarding good teaching practices that goes beyond the role of the university and needs the active participation of the teacher [31].

Reflection on teaching practice concerns all teachers, educators or tutors of all educational levels, who are led by their need to understand and evaluate their teaching practice, identifying mistakes or problems in order to act as efficient as possible [32]. Through reflection teachers can explore more critically their teaching practice allowing them to enhance their professional knowledge. Hence, pre-service teachers could start reflecting on their practice aiming to improve their teaching skills, newly appointed teachers could use reflective practice to increase their knowledge and understanding maximizing their professional development, while experienced teachers through reflection could understand in depth various educational issues that arose during their career because of the enormous educational changes [24]. Reflective practice is a promising method to be used in education allowing people to recapture their experience and use it as an opportunity to learn [27] [33]. Additionally, the process of learning through experience, experiential learning, promotes the development and maintenance of professional expertise [24] [32] [34].

Even though the process of reflection is quite promising in the field of education, several challenges have been encountered that need to be addressed. One significant issue is that reflection is not characterized by conceptual clarity and as a result it has been used differently by different scientists and practitioners [33] [34]. Furthermore, there is high possibility that in many cases reflective activities promote predetermined outcomes turning the reflective process to a memorization process preventing learners self-reflect and brainstorming [35]. Moreover, in many cases reflective activities do not target learning. It is important to design reflective activities within the context of specific aims and consequences, otherwise the expected outcomes might not be accomplished [24]. In many cases, reflection is not being encouraged by the learning context the trainer has set and as a result, the trainees do not focus on their personal experience and do reveal their misunderstanding and uncertainties, undermining their learning [34]. Equally important is the fact that the aims and boundaries of reflection following an activity must be set; otherwise, it is possible to observe ethical dilemmas affecting negatively the relationship between the teacher and a student [34].

Reflection must become a top priority of teacher education programs, as through the reflective process teachers will be able to evaluate their experiences and throughs, especially those coming from their classroom practice and analyze different viewpoints increasing their awareness and understanding [16] [33] [35]. As a result, reflection has been set as a goal of many teacher education programs as there are indications that the integration of reflection within the curriculum resulted in more empowered beginning teachers [16]. Moreover, reflection is included in most teacher competence models and frameworks these days [36] [37].

Nevertheless, despite the fact, the reflection is a key component in most competence models; it is also one of the most difficult challenges for teachers [38]. There are indications that teacher education programs promote superficial cultivation of teacher's reflective skills [39] [40]. Moreover, teacher education focuses on the pro- 
motion of reflection regarding teaching practice and the ways to improve the teaching strategies to respond to the standardized curriculum, ignoring the importance of reflection to the promotion of teacher's professional development [25]. Furthermore, results indicate that beginning teachers do not possess the ability to self-reflect even after receiving relevant education and as a result they face enormous difficulties in critically reflect on their teaching practices [41]. This lack of teacher's reflective skills indicates a failure of teacher education programs [42]. Thus, there is a need to enhance teachers' self-reflection through experiential learning, so as to maximize their expertise [24].

Taking all the above into consideration, reflection is a key point in the professional development of teachers. Reflective practices will allow teachers to detect their strengths and weaknesses and learn through the experiences of their everyday classroom lives. Self-reflection will also enable them to invent new strategies of action and make decisions based on prior experiences. Moreover, by recognizing their own errors and weaknesses teachers can have an explicit picture of their progress and see what needs to be improved. Reflection is the means that will enable them to increase their self-awareness, develop critical thinking and evaluation skills. In addition, reflection encourages metacognition and self-empowerment, enhances creativity and contributes in the improvement of communication, which will help them respond to the new social challenges of the 21 st century.

\subsection{Empathy and Education: Enhancing empathy skills using VR}

Empathy is the ability to place oneself in another's position, participate in what one suffers until complete empathetic identification without the lost of the personal identity [43]. There is no consensus on the meaning of empathy, as it is used by several disciplines and thus the different definitions reflect the differences of the fields [44]. Empathy refers to the ability to enter the position of another person and see the world with his/her own eyes. As stated in Ref. [45] empathy as "a quality shown by individuals which enables them to accept others for who they are, to feel and perceive situations from their perspective and to take a constructive and long-term attitude towards the advancement of their situation by searching for solutions to meet their needs". Empathy is the ability to understand or appreciate how someone else feels [46]. As stated in Ref. [47] empathy is the "capacity to (a) be affected by and share the emotional state of another, (b) assess the reasons for the other's state, and (c) identify with the other, adopting his or her perspective'. Despite the variation in the terminology of the term, all the definitions converge that empathy is the ability of 'predicting, of appreciating the psychological dispositions of a person, his/her perceptions, thoughts, feelings and attitudes as own traits perceiving the other's mentality, his feelings, desires, opinions, and more concretely to predict his behaviours put yourself in another's place, to see the world as he sees it' [48].

Empathy is a very strong communication technique as it promotes the establishment of social interactions and cooperation [46]. The development of empathy skills allows us to enter the position of the other, understand his/her behavior and motives and thus see the world through his/her eyes that is a very strong communication tool. 
The role of empathy is decisive in all sciences today. Hence, empathy is considered an integral part of education and must be an integral part of the pedagogical process to assist with the social and emotional development of students. As stated in Ref. [49], 'understanding of the self in relationship to others is a fundamental element in teaching'. In the context of education, empathy 'refers to the teacher's participation to the pupils' emotions and feelings, to their sharing, to their common experience. It consists in a togetherness with pupils, to the grasp of their inner universe' [48].

Empathic teachers can take on the perspective of their students and respond from that perspective. This allows them to transpose themselves to the position of the student and to decide the best course of action within the limits of a permissible error [48]. The establishment of balanced and strong relationships between students and teachers and teacher's ability to meet their students' needs can increase their student's elf-esteem and self-worth. Additionally, the establishment of strong communication channels between teachers and students affects positively student's cognitive, social and emotional development, while it also increases their sense of belonging to the school [48][50][51][52]. Moreover, empathic teachers who become emotionally involved with their students receive similar responses in return that affect positively student's personal and academic development and their relationships with the others [45].

Empathic teachers can be moral models setting a good example for the students and impart their values to their students expecting them to learn to value other people [45]. However, it seems that the educational system itself undermine teacher's efforts and even though they begin their career with a great deal of concern for others, their lack of empathy training and their everyday school life changes their caring role giving priority to the classroom management and curriculum implementation [45]. Teachers as most people have not been trained and do not poses empathy skills. In the past when societies were smaller, people could more easily understand their neighbors. However, the new living conditions and the modern social and economic problems have led to people who find it hard to express themselves and thus, their problems cannot be understood easily just by observing them. As the school is a microcosm of the society teachers deal everyday with students who are not able to express themselves. It is therefore a necessity for teachers to be trained and enhance their empathy skills in order to be able to help their students but also other people around them.

VR is an 'empathy-inducing medium' [53], which makes it a suitable tool in enhancing empathy skills as it can help people in general to relate to each other and help teachers in particular to relate to their students. The current research explored the possibility to cultivate empathy skills using a VR based approach. This need arose also from the fact that although empathy is considered a key skill for teachers it is not include as a key competence in the various competence models (add references). Another factor that contributed to that was that only in a model proposed outside Europe and specifically by the National Institute of Education-NIE [54] in Singapore empathy is included as a top priority skill. 


\section{Experimental Set-up}

\subsection{The groups}

The experimental investigation included three different classroom scene settings:

- Physical (Real) Classroom space setting (see Figure 1 top)

- Virtual Environment with Realistic Appearance (see Figure 1 middle) that was designed based on real classrooms

- Virtual Environment with Imaginary Appearance (see Figure 1 bottom) that is an imaginary virtual classroom space

The imaginary environment was designed based on suggestions by active and experienced teachers who would prefer to be trained within a virtual world that does not simulate the real classroom that is part of their daily routine.

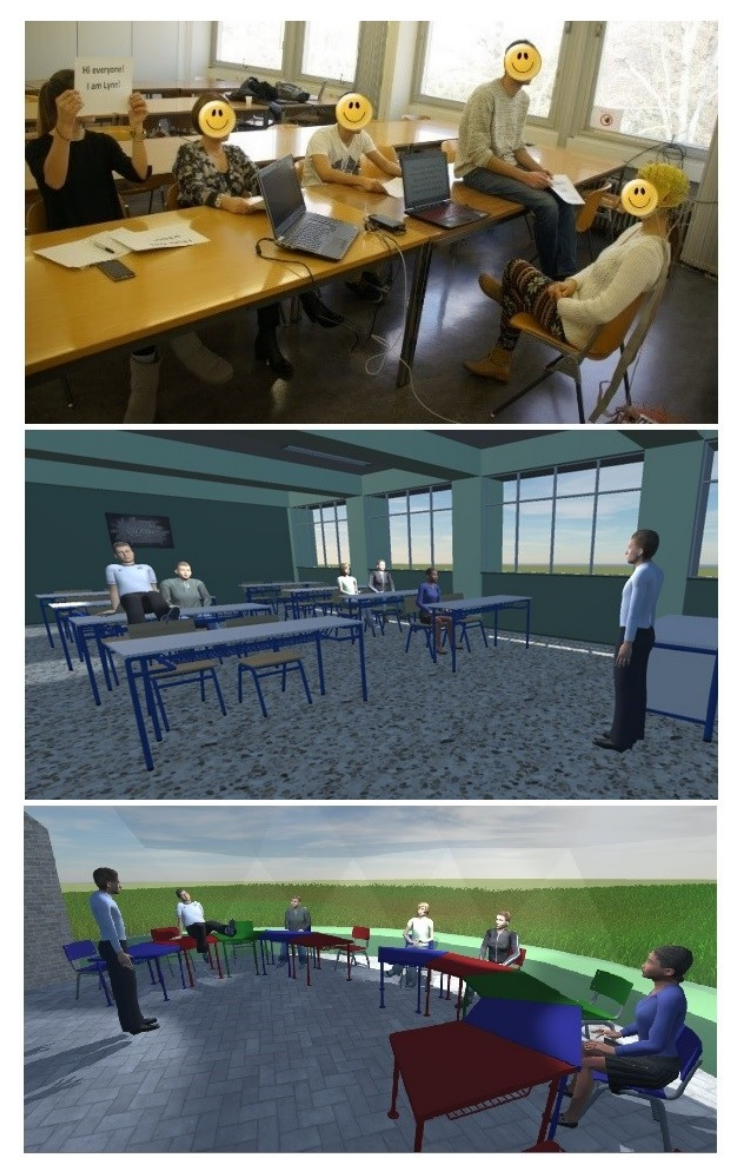

Fig. 1. Physical (Real) Classroom space (top), Virtual Environment with Realistic Appearance (middle) and Virtual Environment with Imaginary Appearance (bottom) 
Three groups, each consisting of 11 participants, took part in the experiment and each group experienced the same scenario but in a different classroom setting among the ones described above [55]. However, the present paper does not aim to analyze the differences between the two virtual worlds and for the presentation of the results the participants are divided into two groups:

- The control group, the Physical Space group (PS.group) experienced the scenario in a physical classroom with real students

- The second group, the Virtual Reality group (VR.group) experienced the scenario in the two virtual classroom environments

\subsection{The scenario}

The scenario dealt with multiculturalism and verbal bullying and its selection was the result of an extensive literature review research, survey and interview conducted with experienced in-service teachers and academic experts regarding the most important problems that teachers face within today's classrooms. The scenario begins with the teacher introducing a new foreign student called Lynn to the classroom. Following her introduction to the class, Lynn receives verbal bulling from her classmates. The user-teacher was given the opportunity to experience the problem from two different perspectives (see Figure 2):

- Perspective I Through the eyes of the student Lynn

- Perspective II Through the eyes of the teacher

The scenario and the dialogues were the same at both perspectives, changing only the camera position allowing the user to experience the two different viewpoints.
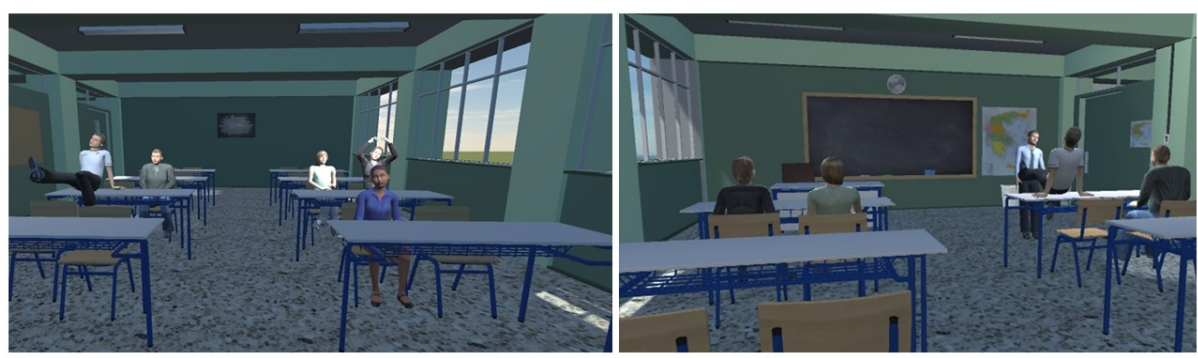

Fig. 2. Experiencing the virtual worlds through the eyes of the student Lynn (right) and through the eyes of the teacher (left)

\subsection{The virtual classroom environment}

The VR system was developed with the UnityC game engine. The 3D avatars (teachers and students) were created using the online software Autodesk ${ }^{\circledR}$ Character Generator and the 3D models (school and objects including desks, chairs etc.) were develop using Maya Autodesk student version. Moreover, the Head Mounted Display 
(HMD) HTC VIVE was used as a means of viewing the application. It is worth mentioning that there are several researches arguing the use of VR in education including the use of a three-dimensional environment displayed on computer screens. However, those researches do not include the use of the special electronic equipment such as HMD glasses such as VIVE. It must be clear that for the needs of the current research VR specific equipment was used.

\section{$4 \quad$ Methodology}

\subsection{The research questions}

The aim of the experiment was to identify the potential of using a VR based approach to enhance the cultivation of reflection and empathy skills. Moreover, the research aimed to identify possible differences regarding reflection skills between the groups that used the VR system and the control group that was trained within a real classroom setting without the use of VR. To achieve the above aims two re-search questions were posed:

- Does the use of VR promote the cultivation of reflection and empathy skills?

- Is there a difference in the cultivation of reflection and empathy skills between participants who used a VR system and those who were trained in a real classroom setting?

\subsection{The sample}

A total of 33 participants ( 22 male and 11 female), took part in the experiment all from higher education sector. Regarding the profile of the respondents in terms of their age $63.6 \%$ are in the age range of 25 to 29 years old $27.3 \%$ in the range of $30-39$ years old, $18.2 \%$ in the range of $50-59$ years old and $9.1 \%$ in the range of $18-24$ years old. In the first group, $54.6 \%$ of the respondents had between 1 to 2 years of teaching experience, while $36.4 \%$ of the respondents indicated no teaching experience at all. On the contrary, in the second group $72.8 \%$ of the respondents had between 1 to 5 years of teaching experience, while in the third group $45.5 \%$ of the respondents had between 1 to 5 years of teaching experience and $36.4 \%$ has between 6 to 10 years of teaching experience. What is significant is the fact that data revealed that most of the participants were unfamiliar with the use of virtual reality.

\subsection{The research tool and the process}

For the measurement of reflection and empathy, a questionnaire was developed based on several instruments concerning reflection and empathy, as none of the already existing instruments responded to the needs of the current research. The questionnaire was pre-tested along with the virtual classroom space by academic experts, and their comments and support lead to several modifications to achieve a clear out- 
come for the participants. The experiment took place in December 2017. Before taking part in the experiment, all participants were informed about the experiment and its purpose, assurances of confidentiality and non-traceability regarding their participation were given along with explanations regarding their right to withdraw at any time and for no reason. After voluntary informed consent was obtained, the scenario was explained to the participants with more details and the experiment began. After the end of the experiment, the participants were asked to complete the questionnaire.

\section{$5 \quad$ Results}

After the data has been collected and analyzed with the use of SPSS software (Statistical Package for Social Sciences). Before the presentation of the results, there is a need to clarify the names of the two groups participated in the experiment and explained in the framework section above: VR.group (Virtual Reality group) and PS.group (Physical Space group).

Cronbach's Alpha coefficient of internal consistency was quite good for the items of the reflection scale (Cronbach s Alpha $=0.88$ ). For the empathy items Cronbach's Alpha coefficient was $0.71>0.7$ indicating an acceptable reliability.

\subsection{Reflection scale results}

The results indicate that reflection is considered an important process for all respondents as the vast majority tend to score from agree to strongly agree in both groups (VR.group $\mathrm{M}=5.18 \mathrm{SD}=.54$, $\mathrm{PS}$.group $\mathrm{M}=5.27 \mathrm{SD}=.47$ ). From the data it can be concluded that participants' experience within the virtual classroom can contribute to the change of their beliefs and ideas regarding multiculturalism and bullying as the majority tended to score from agree to strongly agree (VR.group $\mathrm{M}=5.00 \mathrm{SD}=.41$ ). On the contrary, participants of the control group tend to be more neutral and undecided (PS.group $\mathrm{M}=4.36 \mathrm{SD}=.51$ ). The output states that participants of both groups disagree with teachers disinterest in analyzing student's needs as they tended to score from disagree to strongly disagree (VR.group $\mathrm{M}=4.68 \mathrm{SD}=.48$, PS.group $\mathrm{M}=4.36$ $\mathrm{SD}=.51$ ). The results suggest that the group that used the VR system argued that such an experience can change the way teachers attend the needs of their students, as the participants tended to score from agree to strongly agree (VR.group $\mathrm{M}=5.23 \mathrm{SD}=.43$ ). The majority of the participants in the control group tended to be more undecided and neutral indicating their training experience in the real classroom setting did not have the same impact as the VR experience to the other two groups (PS.group $\mathrm{M}=4.36$ $\mathrm{SD}=.51)$. From the data it can be also concluded that both the VR and the real-time classroom training experience can help teachers change the way they will react on disruptive behavior among my students, nevertheless many of the participants tended to be neutral especially those of the control group (VR.group $\mathrm{M}=4.82 \mathrm{SD}=.73$, PS.group $\mathrm{M}=4.36 \mathrm{SD}=.51$ ). Moreover, the results indicate that training both via VR and real-time can help teachers discover faults in their interaction with students that they previously believed to be right as the participants tended to score from agree to 
strongly agree, however, many of the participants tended to be neutral and undecided in both groups (VR.group $\mathrm{M}=4.82 \mathrm{SD}=.79$, PS.group $\mathrm{M}=4.55 \mathrm{SD}=.52$ ). Based on the questionnaire responses it can be concluded that the participants who used the VR system indicated that they agree / strongly agree that a VR experience can offer them the ability to enter their student's position, while the participants of the control group tended to be more neutral regarding entering their student's position (VR.group $\mathrm{M}=5.55 \mathrm{SD}=.51$, PS.group $\mathrm{M}=4.36 \mathrm{SD}=.51$ ). Furthermore, the results suggest that VR can promote teacher's ability to provide improved support to students of other racial and ethnic groups. The majority of the participants that used the VR system tended to score from agree to strongly agree (VR.group $\mathrm{M}=5.00 \mathrm{SD}=.62$ ), while the participants of the control group scored lower tended from disagree to agree, indicating that their training in the real classroom did not seem to promote at high level their ability to support more students belonging to racial and ethnic minority groups (PS.group $\mathrm{M}=4.09 \mathrm{SD}=.70)$.

The results from the tests of normality (namely the Kolmogorov-Smirnov Test and the Shapiro-Wilk Test), revealed that most of the items are below 0.05 , therefore, the data significantly deviate from a normal distribution and non-parametric tests were used. Mann-Whitney U test indicated statistically significant differences between the two groups in some of the reflection scale items. There was a statistically significant difference between VR and PS group regarding the impact of the VR experience and the real-time classroom training on challenging teachers' firmly held ideas about the issues of multiculturalism and bullying $(U=54.5, \mathrm{p}=.003)$ (Figure 3 top left). Moreover, Mann-Whitney $U$ test revealed that there was a statistically significant difference between the two groups regarding changing the way that teachers attend the needs of the students $(\mathrm{U}=34, \mathrm{p}=.000)$ (Figure 3 top right). Another statistically significant difference between the two groups was found regarding teacher's ability to enter the student's position $(\mathrm{U}=20, \mathrm{p}=.000$ ) (Figure 3 bottom left). Furthermore, Mann-Whitney $U$ test revealed a statistically significant difference between the VR and the control group regarding teacher's ability to support more efficiently students belonging to racial and ethnic minority groups $(\mathrm{U}=45, \mathrm{p}=.001)$ (Figure 3 bottom right).

\subsection{Empathy scale results}

The mean scores do not indicate significant differences between the two groups regarding empathy. Respondents of both groups tended to agree that teachers should be able to predict the feelings of their students (VR.group $\mathrm{M}=4.78, \mathrm{SD}=1.11$, PS.group $\mathrm{M}=5.09, \mathrm{SD}=.83$ ). Respondents of both groups tended from agree to strongly agree that teachers should be able to spot when students are feeling awkward or uncomfortable (VR.group $\mathrm{M}=5.5 \mathrm{SD}=.51$, PS.group $\mathrm{M}=5.18 \mathrm{SD}=.41$ ). According to the results the participants tend from agree to strongly disagree that teachers should try to look at every student's side of a disagreement before making a decision (VR.group $\mathrm{M}=5.18$ $\mathrm{SD}=.67$, PS.group $\mathrm{M}=5.18 \mathrm{SD}=.61$ ). Additionally, respondents of both groups tend to agree that as teachers they should try to understand the students better, by imagining 

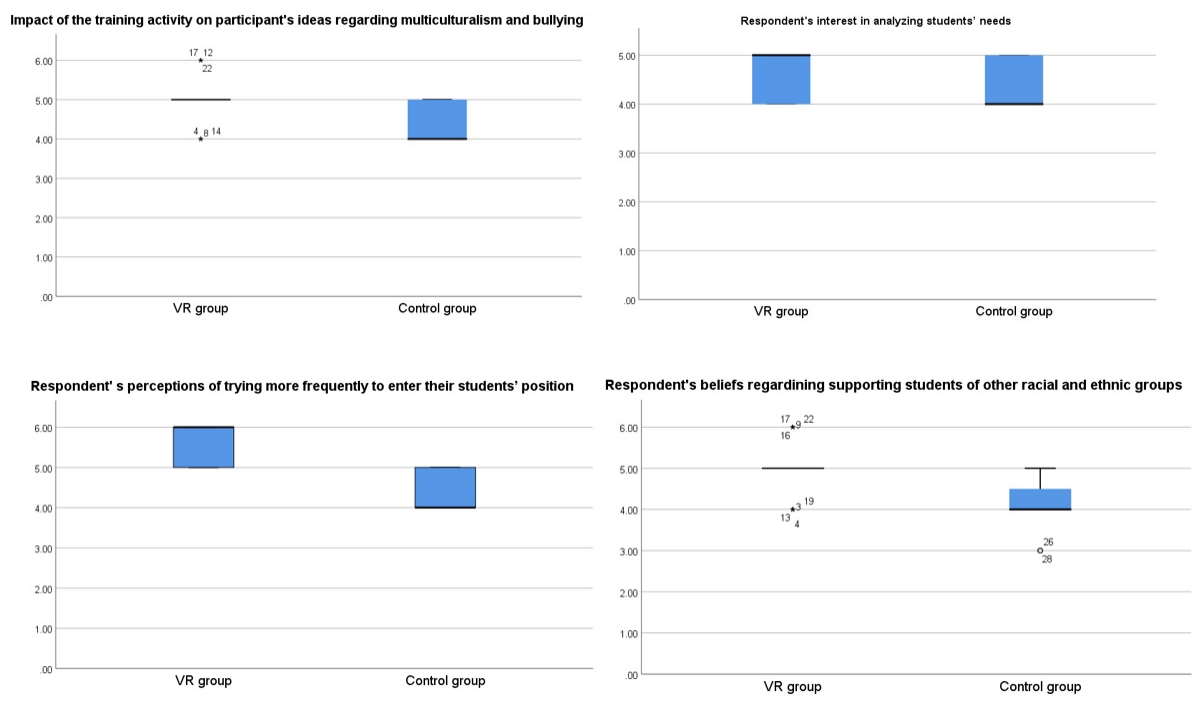

Fig. 3. Plot box presenting the differences between the VR and PS groups in the reflection scale items

how things look from their perspective (VR.group $\mathrm{M}=5.46 \mathrm{SD}=.51$, PS.group $\mathrm{M}=5.27 \mathrm{SD}=.65$ ). regarding teacher's ability to see things from the student's point of view the results indicate that participants of the VR.group tend to be from expressing no opinion to strongly agree $(\mathrm{M}=4.73, \mathrm{SD}=1.39)$, while the participants of the PS.group tend to agree $(\mathrm{M}=5.09, \mathrm{SD}=.83)$. Moreover, the results indicate that regarding teacher's emotional involvement with student's problems the VR.group tend to be from expressing no opinion to strongly agree $(\mathrm{M}=4.00, \mathrm{SD}=1.42)$, while the PS.group $(\mathrm{M}=4.09, \mathrm{SD}=1.30)$ tend from disagree to strongly agree. Both groups tend to agree that teachers they should try to imagine how they would feel in the students' situation, (VR.group $\mathrm{M}=5.18 \mathrm{SD}=.80$, PS.group $\mathrm{M}=5.18 \mathrm{SD}=.41$ ). Regarding teacher's support of students of other racial and ethnic groups, the participants of all groups tend from agree to strongly agree, (VR.group $\mathrm{M}=5.23, \mathrm{SD}=.76$, $\mathrm{PS}$.group $\mathrm{M}=4.91 \mathrm{SD}=.70$ ). Finally, the results indicate that regarding teachers' ability to put himself/herself in the position of someone who is racially and/or ethnically different, the VR.group tend from no opinion to strongly agree $(\mathrm{M}=3.60, \mathrm{SD}=1.26)$, while the participants of the PS.group tend from disagree to agree $(\mathrm{M}=4.73, \mathrm{SD}=.91)$.

The results from the tests of normality (namely the Kolmogorov-Smirnov Test and the Shapiro-Wilk Test), revealed that most of the items are below 0.05 , therefore, the data significantly deviate from a normal distribution and non-parametric tests were used. Mann-Whitney U test did not indicate statistically significant differences between the two groups in the majority of the items of the empathy scale. Nevertheless, the test provided very strong evidence $(p=0.008)$ of a statistically significant difference between the VR and PS group related to teachers' ability to put himself/herself in the position of someone who is racially and/or ethnically different (see Figure 4) 


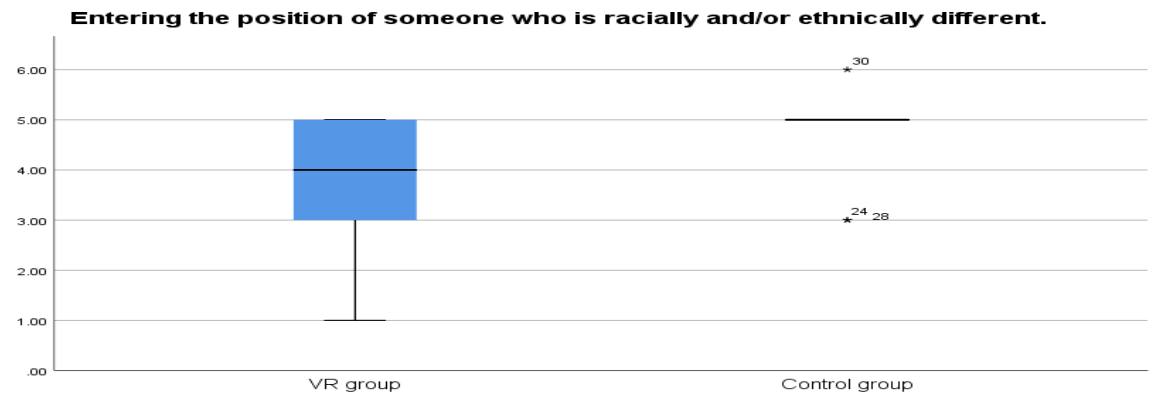

Fig. 4. VR and PS group response regarding respondents' ability to put themselves in the position of someone who is racially and/or ethnically different

\section{Discussion}

The last few years the technological evolution reshaped teaching and learning providing new and innovative strategies to be implemented in the classroom environment including VR [56][57]. VR can have positive effects on students enhancing their cognitive development and motivation as the lesson is becoming more interesting [56]. The question lies in whether the use of VR can have a positive effect in teacher education providing teachers a new way of learning.

The current research aimed to explore the possibility of promoting and cultivating teacher's reflection and empathy skills via the use of a VR based approach. Moreover, another objective was to identify possible differences between the participants who used the VR system and those who were trained without real classroom without using the VR system. The results of the research are promising regarding the potential of using VR based methodology as part of teacher training regarding the cultivation of reflection and empathy skills.

The results indicate that participants from both groups consider the process of reflection significant. Nevertheless, experimental results indicate that the control group that did not use the VR system scored lowered in all items of the reflection scale and tended to be more undecided regarding the effectiveness of their training within the real classroom setting. On the contrary, experimental results indicate that the VR experience can contribute to a higher level to the change of beliefs and ideas regarding multiculturalism and bullying, change the way teachers attend the needs of their students and react on disruptive behavior among the students. Moreover, the VR experience offered the participants the opportunity to enter the student's position and experience bullying through the student's viewpoint, challenging some firmly held ideas and promoting more support to students of racial and ethnic minority groups. Within the VR environment, the camera was placed in a way allowing the participants to see themselves as being in the body of the student, offering a more immersive experience and deeper understanding of the problem. This could not be achieved in the real classroom setting where the participants felt more like themselves, resulting in more neutral scores. It seems that although there are indications that reflection skills 
were cultivated at all groups, the VR based approach was more effective encouraging reflection and understanding of different views at a higher level. The key point consists in the ability of VR to offer the user the opportunity to view a scenario from the eyes of a different person, making their experience a unique learning opportunity. The great variation of different point of views does not seem possible to be achieved in a real classroom setting, and as a result, multiple perspectives reflection cannot be achieved.

From the data, it can also be concluded that empathy was cultivated to both groups. Both groups identified the importance of entering the students' position in order to understand his/her perspective to take the proper course of action that will meet the student's needs. The results did not reveal significant differences between the two groups except from one item of the empathy scale related to teachers' ability to put himself/herself in the position of a student who is racially and/or ethnically different. The results revealed a significant difference between the participants that used the VR system and those who were trained in the real classroom, as those experienced the virtual classroom space claimed that teachers can put himself/herself in the position of someone who is racially and/or ethnically different, while the physical group tend to disagree. The results indicate that the use of the VR system and the opportunity to view a scenario from the eyes of a different person affected more the cultivation of empathy skills towards foreign students to the group that used the virtual classroom as they scored higher to the scale, while the control group tended to be undecided.

Overall, there are several indications regarding the effective use of VR for the cultivation of reflection and empathy skills. However, further research is required to investigate the impact of the VR system on the cultivation of those competencies. A new scenario is already under development with several modifications based on the input provided from the experiment that was conducted and after close collaboration with psychologists and experts from the educational field. Future experiments will add more light on the impact of VR to the cultivation of reflection and empathy skills.

\section{$7 \quad$ Acknowledgement}

Authors acknowledge funding from the European Union's Horizon 2020 Framework Programme through NOTRE Project (H2020-TWINN-2015, Grant Agreement Number: 692058). Moreover, we would like to acknowledge with gratitude the support from MIRALab team, University of Geneva, without whom the experiments would not have been conducted. Finally, we would like to express our deep appreciation to the participants of this research, who generously shared their time for the purposes of this research.

\section{References}

[1] European Commission (2015). Shaping career-long perspectives on teaching: A guide on policies to improve Initial Teacher Education. Retrieved from http://ec.europa.eu/education/library/reports/initial-teacher-education_en.pdf 
[2] Darling-Hammond, L., Hammerness, K., Grossman, P., Rust, F., \& Shulman, L. (2005). The design of teacher education programs. In L. Darling-Hammond and J. Bransford (Eds.), Preparing teachers for a changing world: What teachers should learn and be able to do (pp. 390-442). San Francisco: Jossey-Bass.

[3] Caena, F. (2014). Initial teacher education in Europe: an overview of policy issues. Retrieved September 7, 2015 from http://ec.europa.eu/education/policy/strategicframework/expert-groups/documents/initial-teacher-education_en.pdf

[4] Hagger, H. \& McIntyre, D. (2006). Learning teaching from teachers. Realizing the potential of school-based teacher education. Maidenhead: Open University Press.

[5] Schwille, J. \& Dembélé, M. (2007). Global perspectives on teacher learning: improving policy and practice. Paris: UNESCO.

[6] Woolfolk, A. (2005). Educational psychology (9th Edition). USA: Pearson Education, Inc.

[7] Lou, M. (2017). A Virtual Reality Teaching System for Graphic Design Course. International Journal of Emerging Technologies in Learning (iJET), 12(09), 117-129. https://doi.org/10.3991/ijet.v12i09.7492

[8] Freina, L., \& Ott, M. (2015). A literature review on immersive virtual reality in education: state of the art and perspectives. eLearning \& Software for Education, 1 (1).

[9] Stavroulia, K.E., Ruiz-Harisiou, A., Manouchou, E., Georgiou, K., Sella, F., \& Lanitis, A. (2016). A 3D Virtual Environment for Training Teachers to Identify Bullying. In the proceedings of the 18th IEEE Mediterranean Electrotecnical Conference (MELECON2016), April 18 - 20, 2016, Limassol, Cyprus. https://doi.org/10.1109/MELCON.2016.7495417

[10] Manouchou, E., Stavroulia, K. E., RuizHarisiou, A., Georgiou, K.,Sella, F. \& Lanitis, A. (2016). A Feasi-bility Study on Using Virtual Reality for Understanding Deficiencies of High School Students. In the pro-ceedings of the 18th IEEE Mediterranean Electrotecnical Conference (MELECON2016), April 18 - 20, 2016, Limassol, Cyprus. https://doi.org/10.1109/MELCON.2016.7495418

[11] Dieker, L., Hynes, M., Hughes, C., \& Smith, E. (2008). Implications of mixed reality and simulation technologies on special education and teacher preparation. Focus on Exceptional Children, 40(6), 1. https://doi.org/10.17161/foec.v40i6.6877

[12] Huang, M. P., \& Alessi, N. E. (1998). Current limitations into the application of virtual reality to mental health research. Studies in health technology and informatics, 63-66.

[13] Eschenbrenner, B., Nah, F. F. H., \& Siau, K. (2008). 3-D virtual worlds in education: Applications, benefits, issues, and opportunities. Journal of Database Management (JDM), 19(4), 91-110. https://doi.org/10.4018/jdm.2008100106

[14] Parsons, T. D., Bowerly, T., Buckwalter, J. G., \& Rizzo, A. A. (2007). A controlled clinical comparison of attention performance in children with ADHD in a virtual reality classroom compared to standard neuropsychological methods. Child Neuropsychology, 13(4), 363-381. https://doi.org/10.1080/13825580600943473

[15] Aiello, P., D'Elia, F., Di Tore, S., \& Sibilio, M. (2012). A constructivist approach to virtual reality for experiential learning. E-Learning and Digital Media, 9(3), 317-324. https://doi.org/10.2304/elea.2012.9.3.317

[16] Yost, D. S., Sentner, S. M., \& Forlenza-Bailey, A. (2000). An examination of the construct of critical re-flection: Implications for teacher education programming in the $21 \mathrm{st}$ century. Journal of teacher education, 51(1): 39-49. https://doi.org/10.1177/002248710005100105

[17] Romano, D. M., \& Brna, P. (2001). Presence and reflection in training: Support for learning to improve quality decision-making skills under time limitations. CyberPsychology \& Behavior, 4(2): 265-277. https://doi.org/10.1089/109493101300117947 
[18] Schön, D. A. (1991). The Reflective Practitioner: How professionals think in action, England, Ashgate.

[19] Allen, W. C. (2006). Overview and evolution of the ADDIE training system. Advances in Developing Human Resources, 8(4), 430-441. https://doi.org/10.1177/1523422306292942

[20] Peterson, C. (2003). Bringing ADDIE to life: Instructional design at its best. Journal of Educational Multimedia and Hypermedia, 12(3), 227-241.

[21] Stavroulia, K. E., \& Lanitis, A. (2018). A systematic virtual reality-based approach to support the professional development of teachers. In Proceedings of the International Conference on Information Communication Technologies in Education (ICICTE 2018) (pp. 29-38).

[22] Seibert, W. K. \& Daudelin, W. M. (1999). The Role of Reflection in Managerial Learning: Theory, Re-search and Practice. Westport, USA: Quorum Books.

[23] Luhmann, N. and Schorr, K.-E. (2000). Problems of reflection in the system of education. New York: Waxmann.

[24] Pollard, A. (2005). Reflective teaching (2nd Ed.). London: CONTINUUM.

[25] Zeichner, K., \& Liu, K. Y. (2010). A critical analysis of reflection as a goal for teacher education. In Handbook of reflection and reflective inquiry (pp. 67-84). Springer US. https://doi.org/10.1007/978-0-387-85744-2 4

[26] Dewey, J. (1933). How we think: a restatement of the relation of reflective thinking to the educative process. Boston: DC Heath and Company.

[27] Hinett, K., \& Varnava, T. (2002). Developing reflective practice in legal education (p. 51). Coventry: UK Centre for Legal Education.

[28] Seibert, K. W., \& Daudelin, M. W. (1999). The role of reflection in managerial learning: Theory, research, and practice. Quorum Books.

[29] Bengtsson, J. (1995). What is reflection? On reflection in the teaching profession and teacher education. Teachers and Teaching, 1(1): 23-32. https://doi.org/10.1080/1354060950010103

[30] Dewey, J. (1966). The relationship of theory to practice. In M. Borrowman (Ed.), Teacher education in America: A documentary history. New York: Teachers College Press.

[31] Zeichner, K., \& Liu, K. Y. (2010). A critical analysis of reflection as a goal for teacher education. In Handbook of reflection and reflective inquiry (pp. 67-84). Springer US. https://doi.org/10.1007/978-0-387-85744-2 4

[32] Harrison, 2008). Professional development and the reflective practitioner. In S. Dymoke \& J. Harrison (Eds.), Reflecting teaching and learning. A guide to professional issues for beginning secondary teachers (pp. 7-44). London: SAGE.

[33] Procee, H. (2006). Reflection in education: A Kantian epistemology. Educational Theory, 56(3), 237-253. https://doi.org/10.1111/j.1741-5446.2006.00225.x

[34] Boud, D., \& Walker, D. (1998). Promoting reflection in professional courses: The challenge of context. Studies in higher education, 23(2): 191-206. https://doi.org/10.1080/03075079812331380384

[35] Körkkö, M., Kyrö-Ämmälä, O., \& Turunen, T. (2016). Professional development through reflection in teacher education. Teaching and Teacher Education, 55: 198-206. https://doi.org/10.1016/j.tate.2016.01.014

[36] Caena, F. (2011). Literature review Teachers' core competences: requirements and development. Edu-cation and training, 2020. Retrieved from http://ec.europa.eu/dgs/education_culture/repository/education/policy/strategicframework/doc/teacher-competences_en.pdf 
[37] European Commission (2013). Supporting the Teaching Professions for Better Learning Outcomes. Re-trieved from European Commission website http://eurlex.europa.eu/LexUriServ/LexUriServ.do?uri=SWD:2012:0374:FIN:EN:PDF

[38] Hagger, H. \& McIntyre, D. (2006). Learning teaching from teachers. Realizing the potential of school-based teacher education. Maidenhead: Open University Press.

[39] Calderhead, J. (1989). Reflective teaching and teacher education. Teaching and teacher education, 5(1): 43-51. https://doi.org/10.1016/0742-051X(89)90018-8

[40] Conway, P. F. (2001). Anticipatory reflection while learning to teach: From a temporally truncated to a temporally distributed model of reflection in teacher education. Teaching and teacher education, 17(1): 89-106. https://doi.org/10.1016/S0742-051X(00)00040-8

[41] Avgitidou, S., \& Hatzoglou, V. (2013). Educating the reflective practitioner in the context of teaching practice: The contribution of journal entries. In A. Androusou and S. Avgitidou (Eds.), Teaching Practice during Initial Teacher Education: Research perspectives (pp. 97-124) (in Greek). Athens: National Kapodistrian University of Athens.

[42] Poulou, M. \& Haniotakis, N. (2006). Teacher candidates' reflection relative to practice: A first attempt (in Greek). Educational Sciences, 1: 87-97.

[43] Kirman, A., \& Teschl, M. (2010). Selfish or selfless? The role of empathy in economics. Philosophical Transactions of the Royal Society of London B: Biological Sciences, 365(1538), 303-317. https://doi.org/10.1098/rstb.2009.0192

[44] Gerdes, K. E. (2011). Empathy, sympathy, and pity: 21st-century definitions and implications for practice and research. Journal of Social Service Research, 37(3), 230-241. https://doi.org/10.1080/01488376.2011.564027

[45] Cooper, B. (2004). Empathy, interaction and caring: Teachers' roles in a constrained environment. Pastoral Care in Education, 22(3), 12-21. https://doi.org/10.1111/j.02643944.2004.00299.x

[46] Stepien, K. A., \& Baernstein, A. (2006). Educating for empathy. Journal of general internal medicine, 21(5), 524-530. https://doi.org/10.1111/j.1525-1497.2006.00443.x

[47] De Waal, F. B. (2008). Putting the altruism back into altruism: the evolution of empathy. Annu. Rev. Psychol., 59, 279-300.

https://doi.org/10.1146/annurev.psych.59.103006.093625

[48] Lăzărescu, M. P. (2013). The Structure and Dynamics of the Teacher's Empathic Behavior. Procedia-Social and Behavioral Sciences, 78, 511-515. https://doi.org/10.1016/j.sbspro.2013.04.341

[49] Hollingsworth, S., Dybdahl, M., \& Minarik, L. T. (1993). By chart and chance and passion: The importance of relational knowing in learning to teach. Curriculum inquiry, 23(1), 5-35. https://doi.org/10.1080/03626784.1993.11076103

[50] Goroshit, M., \& Hen, M. (2014). Does Emotional Self-efficacy Predict Teachers' Selfefficacy and Empathy?. Journal of Education and Training Studies, 2(3), 26-32. https://doi.org/10.11114/jets.v2i3.359

[51] Malikiosi-Loizou, M. (2001). Counseling psychology in education. From theory to practice (in Greek). Athens: Greek Letters.

[52] McAllister, G., \& Irvine, J. J. (2002). The role of empathy in teaching culturally diverse students: A qualitative study of teachers' beliefs. Journal of Teacher Education, 53(5), 433-443. https://doi.org/10.1177/002248702237397

[53] Carey, K., Micheli, M., Saltz, E., Oden Choi, J., Rosenbloom, J., Hammer, J. (2017). Toward Measuring Empathy in Virtual Reality. CHI PLAY'17 Extended Abstracts, October 15-18, 2017, Amsterdam, The Netherlands. Available at: https://www.researchgate.net/publication/320315148_Toward_Measuring_Empathy_in_V irtual_Reality 
[54] National Science Foundation -NSF (2003). Teacher professional continuum program solicitation. NSF 03-534. Retrieved from http://www.nsf.gov/pubs/2003/nsf03534/nsf03534.htm

[55] Stavroulia, K. E., Baka, E., Lanitis, A., \& Magnenat-Thalmann, N. (2018, June). Designing a virtual environment for teacher training: Enhancing presence and empathy. In Proceedings of Computer Graphics International 2018 (pp. 273-282). ACM. https://doi.org/10.1145/3208159.3208177

[56] Nadan, T., Alexandrov, V., Jamieson, R., \& Watson, K. (2011). Is virtual reality a memorable experience in an educational context?. International Journal of Emerging Technologies in Learning (iJET), 6(1). https://doi.org/10.3991/ijet.v6i1.1433

[57] Chang, X. Q., Zhang, D. H., \& Jin, X. X. (2016). Application of Virtual Reality Technology in Distance Learning. International Journal of Emerging Technologies in Learning (iJET), 11(11), 76-79. https://doi.org/10.3991/ijet.v11i11.6257

\section{Authors}

Kalliopi Evangelia Stavroulia is a $\mathrm{PhD}$ student at the Department of Multimedia and Graphic Arts of the Cyprus University of Technology. She holds an MSc in the Design and Development of Computer Games and Interactive Technologies from Cyprus University of Technology and University of Cyprus (2016). Her research interests focus on the domain of new technologies and specifically in the use of virtual reality, serious games, simulations in the field of education of any educational level.

Andreas Lanitis is a Professor in the Department of Multimedia and Graphic Arts, Cyprus University of Technology and director of the Visual Media Computing Research Lab. Andreas also leads a Multidisciplinary Research Group in the Research Centre on Interactive Media Smart Systems and Emerging Technologies (rise.org.cy). His research interests include Biometrics, Computer Vision and Virtual Reality. He has published more than 130 papers in scientific journals, edited books and conference proceedings.

This article is a revised version of a paper presented at the International Conference on Interactive Collaborative Learning (ICL2018), held September 2018, in Kos, Greece. Article submitted 2018-11-30. Resubmitted 2019-01-17. Final acceptance 2019-01-19. Final version published as submitted by the authors. 